\title{
STATE OF THE ART OF THE LANDSCAPE ARCHITECTURE SPATIAL DATA MODEL FROM A GEOSPATIAL PERSPECTIVE
}

\author{
A. Kastuari ${ }^{\text {a }}$, D. Suwardhi ${ }^{\text {a }}$, H. Hanan ${ }^{\text {b }}$, K. Wikantika ${ }^{a}$ \\ ${ }^{a}$ Remote Sensing \& Geographic Information Science Research Group, Faculty of Earth Science and Engineering, Institute of \\ Technology Bandung, Bandung, INDONESIA \\ Email: aminah.kastuari@gmail.com,deni@gd.itb.ac.id, ketut@gd.itb.ac.id \\ ${ }^{\mathrm{b}}$ Architectural History, Theory and Criticism Research Group; School of Architecture, Planning, and Policy Development, Institute \\ of Technology Bandung, Bandung, INDONESIA \\ email: hhanan@ar.itb.ac.id
}

Commission IV, WG IV/7

KEY WORDS: 3D GIS, CityGML, geodesign, landscape architecture

\begin{abstract}
:
Spatial data and information had been used for some time in planning or landscape design. For a long time, architects were using spatial data in the form of topographic map for their designs. This method is not efficient, and it is also not more accurate than using spatial analysis by utilizing GIS. Architects are sometimes also only accentuating the aesthetical aspect for their design, but not taking landscape process into account which could cause the design could be not suitable for its use and its purpose. Nowadays, GIS role in landscape architecture has been formalized by the emergence of Geodesign terminology that starts in Representation Model and ends in Decision Model. The development of GIS could be seen in several fields of science that now have the urgency to use 3 dimensional GIS, such as in: 3D urban planning, flood modeling, or landscape planning. In this fields, 3 dimensional GIS is able to support the steps in modeling, analysis, management, and integration from related data, that describe the human activities and geophysics phenomena in more realistic way. Also, by applying 3D GIS and geodesign in landscape design, geomorphology information can be better presented and assessed. In some research, it is mentioned that the development of 3D GIS is not established yet, either in its 3D data structure, or in its spatial analysis function. This study literature will able to accommodate those problems by providing information on existing development of 3D GIS for landscape architecture, data modeling, the data accuracy, representation of data that is needed by landscape architecture purpose, specifically in the river area.
\end{abstract}

\section{BACKGROUND}

From several definitions of landscape architecture, it could be summarized that landscape architecture is the design, planning, management and land arrangement which integrates science and art, for the benefit of humans, taking into account the mutual interaction between the environment and man and between human.

Architects tend to only use GIS (Geographic Information System) for the base map or landuse or visualization, but GIS function is beyond that. GIS provides dynamic way to represent a pattern that is invisible and contextual relationships throughout the researched object. GIS is able to help the planning cycle in landscape architecture. Data capturing for inventory, analysis on scientific base, defining objectives, and alternative scenarios of future impacts and planning can be done using GIS (Pietsch, 2012)

One of the stages in the design of landscape architecture is spatial analysis. Spatial analysis that based on database can help architects to perform the analysis quickly and scientifically, which means helping architects to have knowledge and understanding of current conditions to be used in objective design, and to present a basis for the stages of planning and design $(\mathrm{Xu}, 2011)$.

2-dimensional (2D) GIS is not able to describe the earth in accordance with reality or close to reality, because the earth is a three-dimensional field. Some fields of science are already requiring 3D GIS such as: 3D urban planning, flood modeling, as well as landscape planning (Stoter and Zlatanova, 2003) to support the steps in the modeling, analysis, management, and integration of related data, which describe human activity and geophysical phenomena more realistically (Breunig and Zlatanova, 2011). 3D model could improve understanding on the real world since it is easier for everyone to understand, could help better on communication of the data since 3D makes it easier to articulate ideas, and it could solve 3D problems since some spatial problems can only be solved in 3D. 3D GIS is a 3 dimensional Geographic Information System, which is not only descrives the real world visualization in 3 dimensional view, but it is also the data modelling, geo-objects, structuring, 
manipulation, and spatial analysis in 3 dimensional-field (Stoter and Zlatanova, 2003).

In this paper, the requirements for building $3 \mathrm{D}$ model in landscape architecture will be targeted in the river area. River has certain definite environmental, social, cultural and economic values, as well. Rivers have many functions like providing connection between landscapes and communities and they also gather people around the same idea for a creative and sustainable environment. Floodplains are susceptible to dangers of flooding in relation with the human and natural activities (Cengiz, 2013). In order to achieve the suistanable landscape in the river area, it is important to take human behavior, flood risk, morphology, and ecology structure into account.

To help understand the modeling that will be used in the landscape design and planning, the advantages of geospatial data for landscape architecture will be discussed.

This paper is written as preliminary study for research in Three Dimensional Geographic Information System for Landscape Architecture in the river area. That research is implementing fractal method in the landscape design. The researched object of that study is what is the data needed and the data detail requirement for $3 \mathrm{D}$ landscape design and the data acquisition method that could be used in order to achieve certain data resolution and how those requirements could be implemented in landscape architecture.

\section{LANDSCAPE PLANNING \& DESIGN}

\subsection{Landscape architecture}

Landscape planners often use scenarios as a basis for simulating and assessing possible future landscape configurations (alternative futures). A GeoDesign approach to landscape planning could help planners to develop, alter and evaluate alternative futures more rapidly (Albert and Vargas-Moreno, 2012).

The common stages in landscape planning which is illustrated in Figure 1 are (Widodo et al., 2012):

1. Preparation: formulation of the problem and the research purposes as first step, initial information collection, administration preparation.

2. Data collection: including spatial data or social, economy, cultural data that affecting surrounding researched environment. This includes field surveying or literature review.

3. Analysis and synthesis: analyzing the collected data.

4. Landscape planning: This stage begins with the preparation for the concept of landscape planning, which is then presented in the form of spatial planning, circulation, activities and facilities. The concept was later developed in the landscape plan in written or drawn form.

The main stages in landscape planning and designing along with the application of GIS can be seen in Figure 2. The GIS can be applied in spatial analysis, visual expression, and management of spatial data. Spatial analysis with database basis can help architects to do a quick analysis and scientific, which means helping architects to have knowledge and understanding of current conditions to be used in the design objective, and presenting the base for the planning and design stages $(\mathrm{Xu}$, 2011).

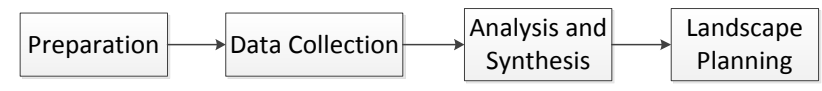

Figure 1 General Methodology in landscape planning, modified from (Widodo et al., 2012)

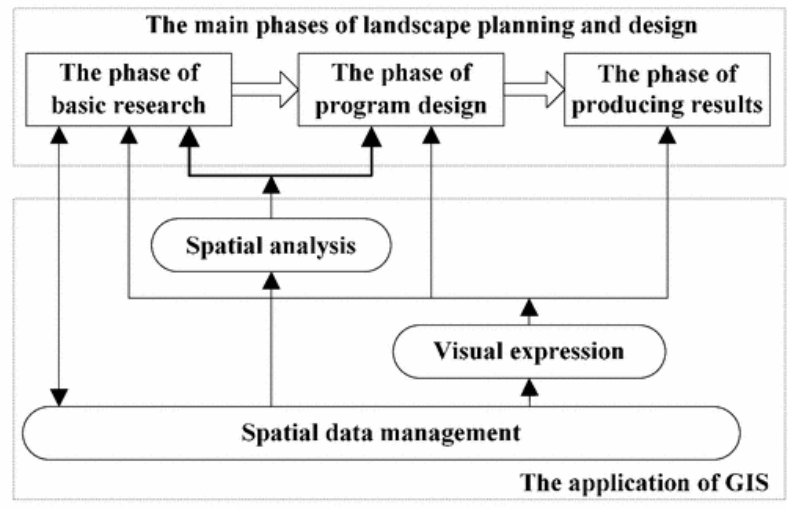

Figure 2 Main steps of landscape planning and design and their application in GIS (Xu, 2011)

\subsection{Geodesign framework}

Geodesign was introduced in 2010. Michael Flaxman and Stephen Irvin describe geodesign as a method which tightly couples the creation of proposals for change with impact simulations informed by geographic contexts and systems thinking, and normally supported by digital technology (Steinitz, 2013). Geodesign is a set of techniques and technologies as an integrated process for planning a built or natural environment. It is a systematic process of measuring, modeling, interpreting, designing, evaluating, and making decisions. Geodesign includes project conceptualization, analysis, design specification, stakeholder participation and collaboration, design creation, simulation, and evaluation (among other stages). (Wheeler, 2010). Geodesign is a new way of thinking about the design process, by utilizing site data with software such as a GIS to create urban or landscape designs.

Geodesign is integration between the geospatial technologies such as GIS with design. By utilizing the spatial databases in GIS, geodesign could benefit from its ability to acquire and manage geospatial information. GIS could also have the ability to analyze geospatial information by using its geoprocessing function. By using GIS database to generate a $3 \mathrm{D}$ model for planning and design, architects will be able to evaluate the design better, creating a way to experience the design beforehand, and enable residents and citizens to become better 
informed about the planned development to facilitate feedback (Tae-Woo Kim et al., 2010, Szukalski, 2011).

Steinitz represents his geodesign framework in 6 steps (Figure 3).

\section{The geodesign framework - by Carl Steinitz}
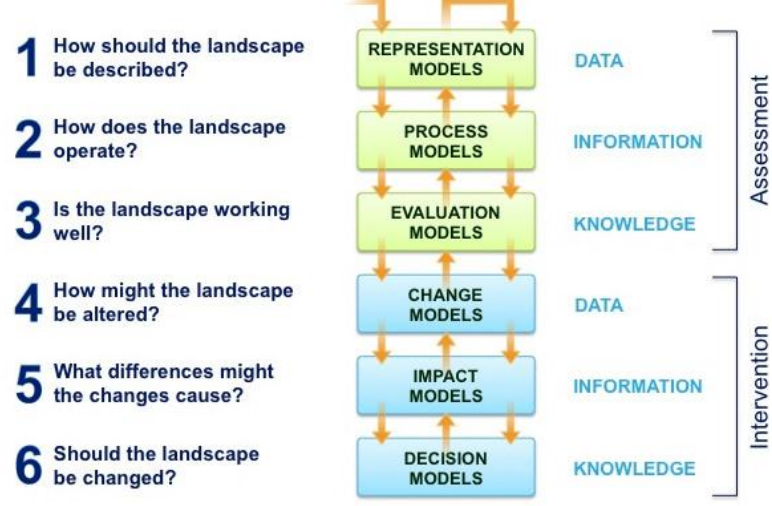

Figure 3 The geodesign framework conceived by Carl Steinitz (Steinitz, 1979).

Albert and Carlos summarize the basic components of geodesign into three categories, which are (Albert and VargasMoreno, 2012):

1. The input process (or the design):

This component is the part of the sketching interface which is the part where the design is still in sketches. It allows quick generation of analyzed alternative designs. It consists of spatial feature with geographical attributes.

2. The evaluation (or the impact):

This component consists of sets of spatial information model. At this stage, the potential impact from the input design is assessed. There are evaluation parameters that are used for the assessment.

3. The result (or the report):

At this stage, the outcomes of the impact evaluation are being communicated to the user in an understandable way. The feedback from the user is used as input in an iterative process.

These processes in geodesign are iterative process.

\section{GEOSPATIAL DATA FOR LANDSCAPE}

In the analysis phase, the landscape architect collects several amount of data and information, such as natural information (e.g., vegetation, mineralogy, geology, hydrology), infrastructure information (e.g., cadaster, buildings, networks, architecture), and social and economic information (e.g., census, economic and geo-political factors and actors, resources, site history) (Favetta and Laurini, 2006).

These data and information are collected from different sources, such as local government, library, internet, etc. In order to understand the needs and requirements for spatial data in landscape architecture, in this chapter will be explained the data resolution, data acquisition technique, and data modeling for landscape architecture.

\subsection{Resolution / Level of Detail Requirement}

In landscape design, it is needed to assess the landscape unit by assessing the physical quality, condition and function of the landscape features and the processes within the landscape unit including landscape, ecological, archaeological and amenity studies.

For design development and assessment, the accurate topographic and land-use maps of the area are needed in order to get better understanding of the parameters in the design.

Dong, et al, studied the evolution and optimization of the landscape patterns in order to increase the ecological security. They used three TM images from 1990, 2000, and 2010 with spatial resolution $30 \mathrm{~m}$ and used them as the basis for landscape classification (Dong et al., 2015).

Parmehr et al., took the images, recorded with a Ground Sampling Distance (GSD) of $10 \mathrm{~cm}$, were processed using the digital photogrammetric system Leica Photogrammetric Suite 9.0 (LPS) to detailed designs of buildings, roads, green zones and playgrounds for landscape planning use (Parmehr et al., 2011).

Cocco et al., implement geodesign to evaluate the urban quality of two neighbor-hoods in Pampulha, Belo Horizonte, Brazil. They evaluate the evolution dynamics of those locations using a multi-criteria analytical approach to explore what could affect the urban quality level and transformation risk in the area based on their spatial phenomenon. The results of the study highlight the role of knowledge as an essential starting point for urban interventions, in order to inform the design by the specific characteristics of the area and the needs of the citizens (Cocco et al., 2015). The data requirements that are used to represent the process in the study area are shown in Table 1.

\begin{tabular}{|c|c|}
\hline Representation Model (layers) & Data source \\
\hline Electric Power Pole (points) & GEMINI Project, CEMIG \\
\hline $\begin{array}{c}\text { B u i l i i n p p o j e c t s } \\
\text { recently approved (points) }\end{array}$ & Period 2009-2013, PRODABEL \\
\hline $\begin{array}{c}\text { Territorial boundaries of the } \\
\text { neighborhoods (polygons) }\end{array}$ & $1: 5000$, PRODABEL \\
\hline Urban plots (polygons) & $1: 5000$, PRODABEL \\
\hline Buildings (polygons) & $1: 5000$, PRODABEL \\
\hline Streets and avenues (polylines) & $1: 5000$, PRODABEL \\
\hline Contours (polylines) & $1: 5000$, PRODABEL \\
\hline $\begin{array}{c}\text { Laser Scanner cloud of points } \\
\text { with attributes of DEM }\end{array}$ & Period 2009, PRODABEL \\
\hline Satellite image & RapidEye 2013, resolution 5 m \\
\hline
\end{tabular}

Table 1 Data sources for the Representation Model in geodesign for urban planning (Cocco et al., 2015) 
Apart from the geodata listed above, the virtual 3D city model can be enhanced by classical georeferenced 2D raster-data sources (e.g., rasterized 2D maps) and vector-data sources (e.g., transportation networks).

\subsection{Data Acquisition Technique}

Architects and planners should be enabled to quickly assess feasibility, errors or areas of conflict between alternative designs. These factors must be considered before choosing the suitable data acquisition technique ( $\mathrm{Li}$ and Petschek, 2014):

1. Survey instruments: survey method, point clouds data generation method, budget;

2. Site conditions: geographical location, scale, landform and physiognomy, composition of ground points and non-ground points;

3. Design tasks: time requirements, design concepts;

4. Variable factors: climatic conditions, season, moving objects.

The main data source for landscape architecture are topographic maps and aerial photographs or satellite images (Sadek et al., 2002), (Parmehr et al., 2011). Land survey is the basis for landscape architecture project. The topographic maps are used to represent, visualized, and shows the geographic reference system of the buildings, roads or transportation systems, trees, terrain, and landuse/landcover.

Whereas the aerial photographs and satellite image are used for better representation of the topographic maps since they are not generalized. Contours and spot heights from topographic map and aerial photographs are used to generate Digital Elevation Model (DEM). Terrestrial photographs of an object from multiple view point are needed to construct the 3D model.

Dong, et al, used three TM images for the basis for landscape classification (Dong et al., 2015). Sadek at al., and Parmehr et al., use terrestrial photographs that were captured using a conventional photographic technique by utilizing digital camera (Sadek et al., 2002), (Parmehr et al., 2011)

Another data acquisition technique is by using laser scanner. Laser scanner could obtain 3D data in high resolution rapidly. Landscape planning could benefit from the laser scanning method.

$\mathrm{Li}$ and Petschek did an experiment in applying a 3D-laser scanner in a landscape design project (Li and Petschek, 2014). They found this method was easier to achieve high-resolution point clouds data for 3D spatial data, although it has some limitations. This method is not recommended for rainy, foggy and snowy weather conditions, and if there are too many moving targets. It is also not recommended for sites covered with many irregular vegetation or objects, because of the effort and time required to delete noise points in the data processing.

In the virtual 3D city model of Berlin that was researched by Döllner et. al., these geodata sources were used (Döllner et al., 2006):
1. Cadastral Data: The cadastral database delivers the official footprints of buildings and land parcels.

2. Digital Terrain Model: The available grid-based DTMs vary in resolution and extension. DTM of $20 \mathrm{~m}$ resolution builds the framework; a higher-resolution DTM is used for the core part of the virtual 3D city model. In areas of special interest, an explicit 3D model of the terrain surface structure replaces the grid-based DTMs.

3. Aerial Photography: A collection of digital aerial photography is linked to the virtual 3D city model. They can be projected on top of the digital terrain model.

4. Building Models: captured and processed by laserscanning and photogrammetry-based methods. The buildings are represented at various levels of detail, including block-models (LOD-1), geometry-models (LOD-2), architectural models (LOD-3), and detailed indoor models (LOD-4).

5. Versions and Variants: A given city object can be updated and, therefore, have multiple versions. In a similar way, a given area can contain different variants of city object collections.

Sheppard did observation on the impact of using laser scanner for landscape planning. In his research was mentioned that there are some advantages of data that were obtained by laser scanner used in landscape planning which are in visualization, level of detail, high level of trust in data, and the high-tech image (Sheppard, 2004).

There are some consequences of using high detailed 3D data such as the one that were produced from the laser scanner, it could expand our understanding of environmental perceptions, improve public involvement processes, contribute to more informed designs, and manage various visual/spatial phenomena of importance to society in certain landscape types (Sheppard, 2004).

Landscape architects could take advantage of Mobile Mapping System for their needs. Landscape architects could build a database of GIS shapefiles for their design phase of their project before the data is used in the GIS for mapping the landscape objects. These data can be imported into spatial database prior to site mappings. Having shapefiles beforehand can provide a smooth continuity of data throughout the landscape architecture design phase throughout the management phase (Rybka, 2013).

In Table 2 the data acquisition technique and data resolution that is used in landscape architecture, especially for spatial data that is used in river area are mentioned.

Different scales of planning require different data and techniques. Raster data are more useful for planning, because large areas are involved and high resolution is not required. The processing of raster data is much faster than that of vector data, especially in map overlay and buffer analysis. On the other hand, vector data are generally used for district and local action 
area planning because of the need for very high resolution analysis (Rong LIU, 2002).

\begin{tabular}{|c|c|c|c|c|}
\hline No. & Layers & Resolution & $\begin{array}{c}\text { Data } \\
\text { acquisiton }\end{array}$ & Purpose \\
\hline 1 & Topography & $20 \mathrm{~m}$ & $\begin{array}{l}\text { Aerial photo, } \\
\text { satellite image }\end{array}$ & Building footprints \\
\hline \multirow[t]{2}{*}{2} & \multirow[t]{2}{*}{ DTM } & $20 \mathrm{~m}$ & \multirow[t]{2}{*}{$\begin{array}{l}\text { Aerial photo, } \\
\text { satellite image, } \\
\text { laser scanner }\end{array}$} & $\begin{array}{l}\text { For building the } \\
\text { framework }\end{array}$ \\
\hline & & higher-resolution & & $\begin{array}{l}\text { For the core part of } \\
\text { the virtual 3D city } \\
\text { model }\end{array}$ \\
\hline \multirow[t]{2}{*}{3} & \multirow[t]{2}{*}{ Texture } & & Aerial photo & \multirow[t]{2}{*}{$\begin{array}{l}\text { Projected on top of } \\
\text { DTM }\end{array}$} \\
\hline & & $\begin{array}{l}\text { - distance up to } \\
300 \text { meters, } \\
\text { - scanning } \\
\text { density up to } 1 \\
\text { mm, } \\
\text { - scanning } \\
\text { degrees between } \\
270^{\circ} \text { and } 360^{\circ} \text {. }\end{array}$ & Laser scanner & \\
\hline 4 & $\begin{array}{l}\text { Landcover/ } \\
\text { landuse }\end{array}$ & $30 \mathrm{~m}-1000 \mathrm{~m}$ & $\begin{array}{l}\text { Aerial photo, } \\
\text { satellite image }\end{array}$ & $\begin{array}{l}\text { Landcover/landuse } \\
\text { change }\end{array}$ \\
\hline & & & & \begin{tabular}{|l|} 
Vegetation \\
\end{tabular} \\
\hline \multirow[t]{2}{*}{5} & \multirow[t]{2}{*}{ Climate } & \multirow[t]{2}{*}{$50 \mathrm{~km}$} & \multirow[t]{2}{*}{ Satellite image } & For human comfort \\
\hline & & & & $\begin{array}{l}\text { The rainfall } \\
\text { information is used } \\
\text { to predict flood }\end{array}$ \\
\hline 6 & $\begin{array}{l}\text { Physical } \\
\text { typology (soil } \\
\text { type, geology) }\end{array}$ & $30 \mathrm{~m}$ & Satellite image & $\begin{array}{l}\text { Determining the } \\
\text { level of soil fertility }\end{array}$ \\
\hline 7 & $\begin{array}{l}\text { Transportation } \\
\text { network }\end{array}$ & $30 \mathrm{~m}$ & $\begin{array}{l}\text { Aerial photo, } \\
\text { satellite image }\end{array}$ & $\begin{array}{l}\text { For accesibilty and } \\
\text { circulation }\end{array}$ \\
\hline
\end{tabular}

Table 2 Data resolution and their data acquisition technique

\subsection{Data Modeling}

Landscape architecture could be modeled in 2 dimension and 3 dimension, while today it is quite common to capture in models time dimension as well (4 dimension). It is common to visualize changes in landscape architecture works during different seasons of year or to see the impact of the design in the future. Since landscape architecture works with living material, there have not been made perfect systems, which would enable unification of data and easier work with them in the future yet.

Creating 3D models of landscape could go beyond visualization purposes, but they are also a source of wide-range information.

The data model for landscape architecture could be built in a database basis of spatial data.

In reconstruction of urban modeling or landscape, cloud points are the most common and basic data used (Oesau, 2015). Other works propose large city descriptions and offer complementary advantages to the street level representations, in particular fine roof descriptions. Such city descriptions are usually obtained either from airborne data for reconstructing in 3D existing landscapes, or from urban grammars in order to artificially create realistic cities (Lafarge and Mallet, 2012).

Sadek et al. Develop their 3D city model using following modeling technique that is divided into several tasks and short structural summary presented by workflow scheme (Figure 4) (Sadek et al., 2002).

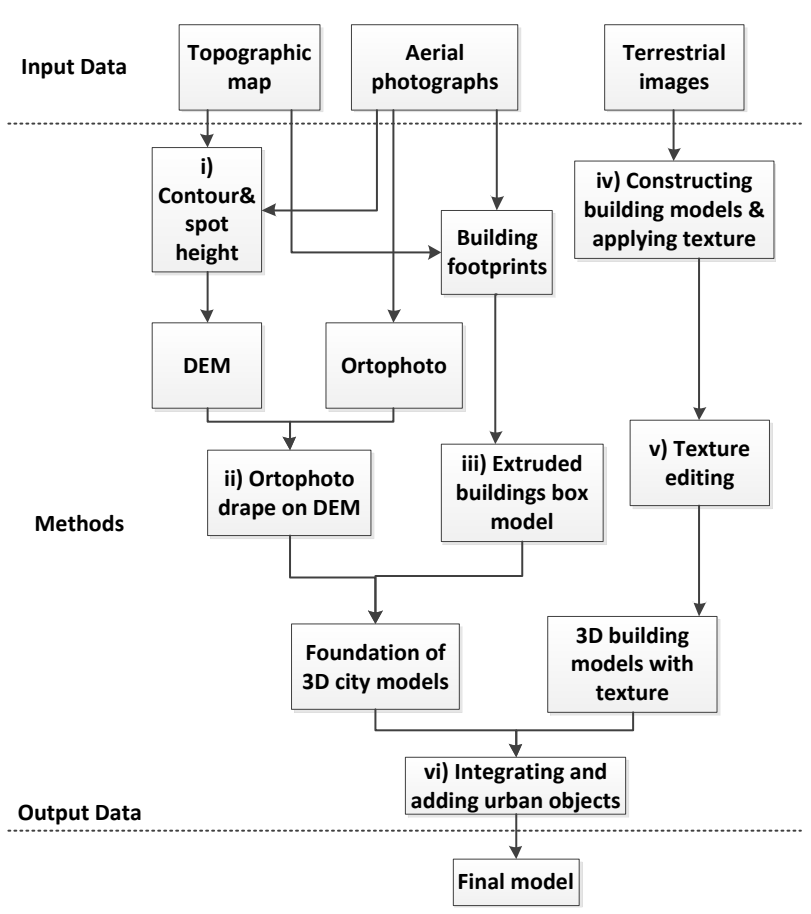

Figure 4 A workflow scheme of methods used in Sadek et al. Project (Sadek et al., 2002)

For data modeling (construction and validation), 3D topology is needed relating to the processing and structuring of data into topological primitives and according to topological data models. In order to determine relations between 3D objects, it should be examined primitive object relationships that build the $3 \mathrm{D}$ objects (3D, 2D, 1D, and 0D), which means the topological requirements of $2 \mathrm{D}$ and $1 \mathrm{D}$ objects had to be determined beforehand (Ghawana and Zlatanova, 2013).

\section{REPRESENTATION MODEL}

The needs for 3D modeling for landscape architecture are growing and expanding rapidly in various fields includes urban planning and design, landscape architecture, environmental visualization and many more.

Modeling objects in 3 dimensional field of the real world is more representative and could be more understandable visually by the planners and designers.

3D city models could represents data that can be used in urban applications and/or landscape architecture, which include buildings, roads or transportation systems, trees, terrain, and 
landuse/landcover. 3D city models is basically a computerized models or digital models of a city (Sadek et al., 2002), (OGC, 2007). There are several representation models that are used in the $3 \mathrm{D}$ planning and design which will be discussed in the latter.

\subsection{CityGML}

The City Geography Markup Language (CityGML) is a new and innovative concept for the modeling and exchange of 3D city and landscape models. CityGML is standardization for interconnected data with different spatial references.

CityGML represents four different common aspects of virtual 3D city models, i.e. semantics, geometry, topology, and appearance for the representation of 3D urban objects that can be shared over different applications which helps to make the cost for maintenance of 3D models more effective.

CityGML is an open data model and XML-based format for the storage and exchange of virtual 3D city models. It is an application schema for the Geography Markup Language version 3.1.1 (GML3), the extendible international standard for spatial data exchange issued by the Open Geospatial Consortium (OGC) and the ISO TC211 (OGC, 2007).

CityGML is built upon a modular structure (Figure 5). The horizontal represents The vertical modules provide the definitions of the different thematic models like building, relief (i.e. digital terrain model), city furniture, land use, water body, and transportation etc. The horizontal modules (CityGML core, appearance, and generics) define structures that are relevant or can be applied to all thematic modules (Kolbe, 2009).

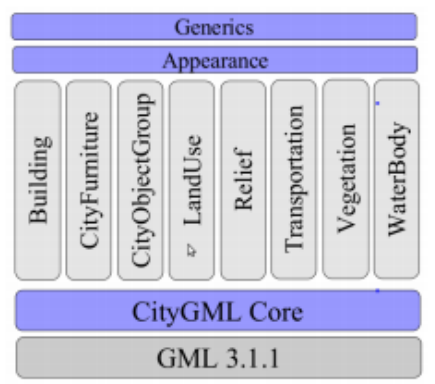

Figure 5 Modularization of CityGML 1.0.0 (Kolbe, 2009)

CityGML represents four different aspects of virtual 3D city models, i.e. semantics, geometry, topology, and appearance. In the CityGML there are five Levels of Detail (LOD) that are more detailed along with the increasing number of LODs, which are (Kolbe, 2009):

5. LOD 0 - regional, landscape

This LOD represents the 2.5 dimensional Digital Terrain Model (DTM) that are laid over aerial image.

6. LOD 1 - city, region

The buildings are represented in 3 dimensional blocks with flat roofs.
7. LOD 2 - city districts, projects

The buildings have structured roof and walls.

8. LOD 3 - architectural models (outside), landmarks The architectural models are more detailed with detailed wall, roof structures, balconies, and projections. The textures are obtained from high resolution image.

9. LOD 4 - architectural models (interior) The interior structures for 3D objects of the architectural model are added.

Each LOD could be mixed in one scene.

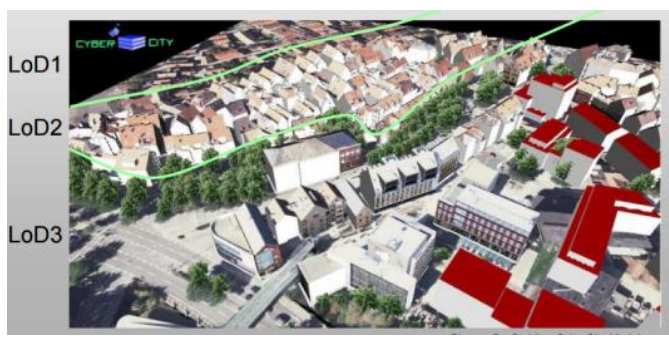

Figure 6 Mixing Levels-of-Detail in one Scene (Kolbe and Gröger, 2005)

Included in the CityGML are generalization hierarchies between thematic classes, aggregations, relations between objects, and spatial properties. These thematic information go beyond graphic exchange formats and allow to employ virtual 3D city models for sophisticated analysis tasks in different application domains like simulations, urban data mining, facility management, and thematic inquiries which could help the design phase on 3D modelling of landscape architecture (Kolbe and Gröger, 2011).

\subsection{Esri CityEngine}

Esri CityEngine is a three-dimensional (3D) modeling software application developed by Esri R\&D Center Zurich (formerly Procedural Inc.) and is specialized in the generation of 3D urban environments. With the procedural modeling approach, CityEngine supports the creation of detailed large-scale 3D city models (CityEngine, 2016). CityEngine uses procedural modeling methods combined with shape and split grammars for generation of 3D content from 2D polygon (Muller et al., 2006). It is the tool of choice for smart 3D city modeling in urban planning, architecture, simulations, game development, and film production (Esri CityEngine). It is the way of modeling that is used to model geometry that is recursive and too tedious to be modeled manually e.g. plants (a single tree pattern can be used to create an entire forest) and landscapes.

Procedural modeling is a modeling by using shape grammars (CGA shape). These shape grammars use production rules by creating more and more details (iterative process). In the context of buildings, the production rules first create a crude volumetric model of a building, called the mass model, then continue to 
structure the facade and finally add details for windows, doors and ornaments. The advantage of this method is it can create hierarchical structure and annotation which could be reused for creating architecture to populate a whole city (Figure 7) (Muller et al., 2006).
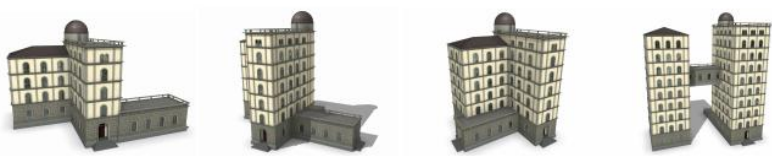

Figure 7 Application of CGA shape on building (Muller et al., 2006)

There are some elements that needed in modeling 3D city using CityEngine, which are:

1. Terrain (heightmap/texture map) and control map layers (images)

2. Street network (automatically/manually created in CityEngine, or imported from DXF, SHP files)

3. Building footprints (automatically/manually created in CityEngine, or imported from DXF, SHP files)

4. CGA rule file

CityEngine allows for various degree of user's control on the city generation, from a semi-automatic way to a 3D landscape generation based on real data, e.g. by importing GIS data and writing ad hoc CGA rule files that describe the required architecture typology (Piccoli, 2013).

\subsection{Visualization and Analysis}

Landscape architects are often charged in tackling interdisciplinary design tasks, where visual communication becomes a key in demonstrating project outcomes, which is why 3D technologies are very useful in landscape architecture. 3D has the advantage on visualizations that is more realistic and could represent more complex data to its viewer. Among the landscape architects, Google SketchUp is the most popular 3D software for visualization, along with ArcGIS, AutoCAD Civil 3D, and 3D Studio Max (Li et al., 2013).

Current 3D technologies allow landscape architects to integrate various data sets and analyses (e.g. hydrology, visual impact assessment) into their work. Another research used 3D analyses within 3D city models using proximity, spread analyses, 3D density and visibility analysis ( $\mathrm{Li}$ et al., 2013).

3D GIS should be able to do following spatial operation (Held et al., 2004):

1. Data retrieval, e.g. Latest information of particular object.

2. Query operation; e.g. retrieve data that meets certain conditions

3. Spatial analysis and semantic data integration, e.g. classification, measurement, overlay operations.

4. Neighborhood operation, e.g. searching, topography operation
5. Connectivity operation, buffering, network.

6. Calculating the distance, area, and additional volume calculation in three-dimensional GIS.

\section{THEMATIC MODEL FOR RIVER LANDSCAPE DESIGN}

In this chapter the thematic model of CityGML for river area is presented in Figure 8. _CityRiverObject is the base class of CityGML. It is a subclass of the class_Feature. All spatial objects inherit the properties from _CityRiverObject. Most thematic classes are (transitively) derived from the basic classes of _Feature and_FeatureCollection. They are the basic notions defined in ISO 19109 and GML3 for the representation of spatial objects and their aggregations. Features contain spatial as well as non-spatial attributes.

In _CityRiverObject there are subclasses that consist of several thematic fields for landscape modeling purpose in the river area, which are: soil type, terrain, transportation, landuse, and climate. In this thematic model, vegetation is derived from landuse and rain fall is derived from climate. The thematic fields were mentioned in Table 2. These objects are not specifically modeled yet. Element names without a prefix are defined in the other module. Each field of CityGML's thematic model is covered by a separate CityGML extension module.

The thematic model of CityGML consists of the class definitions for the most important types of objects within virtual 3D city models. These classes have been identified to be either required or important in many different application areas.

To indicate the extension module defining a respective subclass of _CityRiverObject, the class names in Figure 8 added by prefixes. Each prefix is associated with one CityGML extension module.

Appearance information about a feature's surfaces can be represented by the class Appearance provided by CityGML's Appearance module. Appearance is not derived from _CityRiverObject but from the GML class_Feature. In order to enable city objects to store appearance information, the Appearance module augments the abstract base class _CityRiverObject by the property element appearance using CityGML's Application Domain Extension (ADE) mechanism. It is the extensions to the CityGML data model applying to specific application. Consequently, the appearance property is only available for_CityObject and its thematic subclasses if the Appearance module is supported. Therefore, like the Generics module, the Appearance module has a deliberate impact on any other extension module. In this paper, refers to table, appearance is called texture. This is not to be confused with the texture in CityGML's top level class hierarchy in the CityGML OGC standard since it is mentioned in the standard that the use of TexturedSurface is strongly discouraged (Consortium, 2012). 


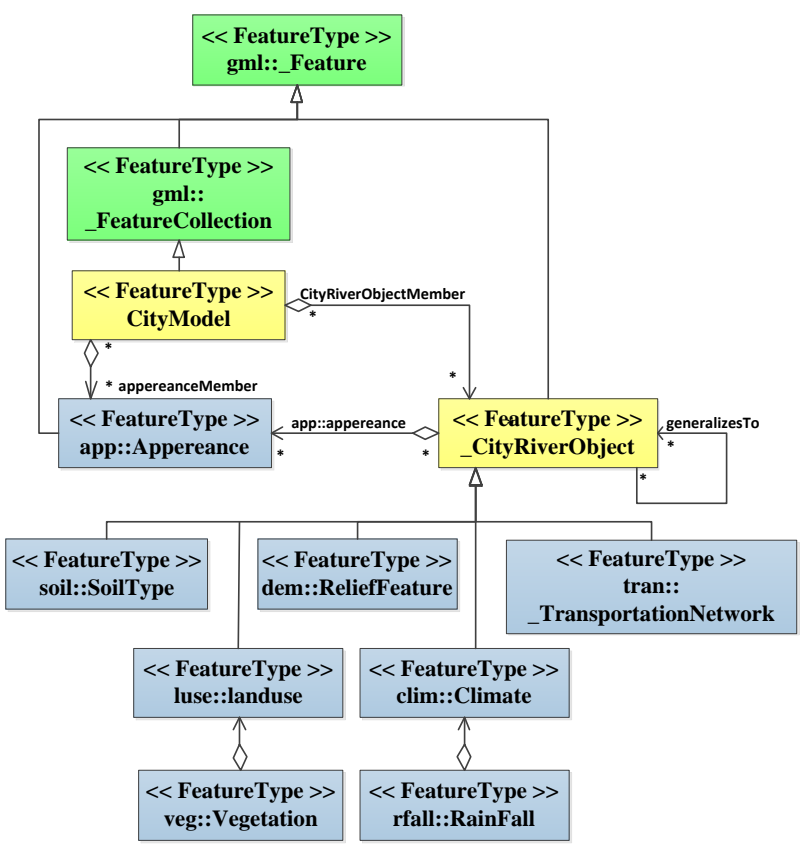

Figure 8 CityGML Thematic Field for Landscape Planning in River Area

\section{DISCUSSION AND CONCLUSION}

The uses of 3D GIS are already being developed in landscape architecture. Conventional two-dimensional GIS is not able to provide an overview of existing conditions that is used in landscape designs realistically and systematically, the architecture had to use their imagination to determine the existing condition.

Development of the use of geospatial data in landscape design can be seen one of the development geodesign. Geodesign able to bring landscape design to another level, and it could create responsible and sustainable solutions to problems related to the existing landscape condition.

By utilizing the spatial databases in GIS, geodesign could benefit from its ability to acquire and manage geospatial information. GIS could also have the ability to analyze geospatial information by using its geoprocessing function. These abilities along with geodesign is not enough to describe the real world if it is only represented in 2 dimensional or even 2.5 dimensional spatial data. It needs 3 dimensional spatial data, which by means not only in 3D graphic representations, but also in 3D modeling, so planner would be able to do spatial analysis in 3 dimensional spaces.

In this paper, several data acquisition techniques related to data resolution that is needed for each thematic layer is described. The thematic layers are adopted from CityGML core thematic layer, by adjusting them for landscape design in the riverbanks area. The layers were taken from several literatures that were researched particularly in the riverbanks area that were using conventional method.

In the future research, the techniques for designing landscape should be described, and the advancement of those techniques should be mentioned. The idea of using fractal method to be implemented in landscape design, especially in 3D form, will be introduced by understanding what kind of geospatial data, what are the requirements and constraints, and what kind of spatial analysis method could be used. Fractal method is used because in recent research that suggests human perceptual systems have evolved to process fractal patterning and that we have a visual preference for images with certain fractal qualities (Perry et al., 2008). Many natural forms and processes possess a common ordering characteristic which could be described by fractal geometry. Fractal concept could be used in the surface modelling for constructing TIN model in order to construct basic model of DTM. Later on, the DTM used along with constraints for landscape architecture could be used to help the architects in their design.

\section{REFERENCES}

Albert, C. and Vargas-Moreno, J. C. 'Testing GeoDesign in Landscape Planning - First Results '. Peer Reviewed Proceedings of the Digital Landscape Architecture 2012 at Anhalt University of Applied Sciences, Anhalt University of Applied Sciences, Berlin.

Breunig, M. and Zlatanova, S. (2011) '3D geo-database research: Retrospective and future directions', Computers \& Geosciences, 37(7), pp. 791-803.

Cengiz, B. 1. (2013) 'Urban River Landscapes', in Ozyavuz, D.M. (ed.) Advances in Landscape Architecture: InTech.

CityEngine (2016): Wikipedia. Available at: https://en.wikipedia.org/wiki/CityEngine (Accessed: 10 Mey 2016).

Cocco, C., Fonseca, B. M. and Campagna, M. 'Applying Geodesign in Urban Planning Case Study of Pampulha, Belo Horizonte, Brazil', 27th International Cartographic Conference, Rio de Janeiro, 1-16.

Author (2012): OGC City Geography Markup Language (CityGML) En-coding Standard.

Döllner, J., Kolbe, T. H., Liecke, F. and Takis Sgouros, K. T. 'The Virtual 3D City Model of Berlin - Managing, Integrating and Communicating Complex Urban Information'. 25th International Symposium on Urban Data Management UDMS, Aalborg, Denmark.

Dong, J., Dai, W., Shao, G. and Xu, J. (2015) 'Ecological Network Construction Based on Minimum Cumulative Resistance for the City of Nanjing, China', ISPRS International Journal of GeoInformation, 4(4), pp. 2045.

Esri CityEngine: Esri. Available at: esri.com/cityengine (Accessed: 13 May 2016).

Favetta, F. and Laurini, R. 'Towards an Efficient Integration, Structure and Exploration of Landscape Architecture Project Information'. 2006 IEEE International Conference on Multimedia and Expo, 9-12 July 2006, 397-400. 
Ghawana, T. and Zlatanova, S. (2013) '3D topology for modelling of urban structures', Geospatial World Weekly.

Held, G., Abdul-Rahman, A. and Zlatanova, S. 'Web 3D GIS for Urban Environments'. International Symposium and Exhibition on Geoinformation, Kuala Lumpur.

Kolbe, T. H. (2009) 'Representing and Exchanging 3D City Models with CityGML', in Lee, J. \& Zlatanova, S. (eds.) 3D Geo-Information Sciences. Berlin, Heidelberg: Springer Berlin Heidelberg, pp. 15-31.

Kolbe, T. H. and Gröger, G. 2005. CityGML - A GML3 Application Profile for virtual 3D City Models. University of Bonn.

Kolbe, T. H. and Gröger, G. (2011) Open Standard for the Modelling and Exchange of Virtual $3 D$ City and Landscape Models.

Lafarge, F. and Mallet, C. (2012) 'Creating large-scale city models from 3D-point clouds: a robust approach with hybrid representation', International Journal of Computer Vision, 99(1), pp. 69-85.

Li, P. and Petschek, P. 'From Landscape Surveying to Landscape Design - A Case Study in Nanjing, P. R. China'. International Conference on Information Technologies in Landscape Architecture, Zurich.

Li, S., Yang, B. and Yan, J. '3D Digital Graphics in Landscape Architecture Professional Practice: Current Conditions in a Nutshell'. Council of Educators in Landscape Architecture (CELA) Conference.

Muller, P., Wonka, P., Haegler, S., Ulmer, A. and Gool, L. V. (2006) 'Procedural modeling of buildings', ACM Trans. Graph., 25(3), pp. 614-623.

Oesau, S. (2015) Geometric modeling of indoor scenes from acquired point data. Université Nice Sophia Antipolis [Online] Available at: https://tel.archivesouvertes.fr/tel-01176721 (Accessed.

Author (2007) Candidate OpenGIS CityGML Implementation Specification (City Geography Markup Language).

Parmehr, E. G., Afary, A. and Basiri, B. (2011) '3D City Models Supporting Tool for Urban Planning and Design ', GIM International.

Perry, S., Reeves, R. and Sim, J. (2008) 'Landscape Design and the Language of Nature', Landscape Review, Vol. 12(No. 2), pp. 3-18.

Piccoli, C. 2013. CityEngine for Archaeology. The Netherlands: Universiteit Leiden.

Pietsch, M. (2012) 'GIS in Landscape Planning', in Ozyavuz, D.M. (ed.) Landscape Planning: InTech.
Rong LIU, P. C., Kaiyun LU, Shilin ZOU 'Core Techniques and Products of Digital Photogrammetry and RS for Urban Infrastructure', ISPRS, Xi'an, China, 6.

Rybka, R. (2013) 'Mobile Mapping the Landscape', LiDARmag. Sadek, E. S. S. B. M., Ali, S. J. B. S. and Kadzim, M. R. B. M. 2002. The Design and Development of a Virtual 3D City Model Malaysia: UiTM.

Sheppard, S. R. J. (2004) 'Laser-Scanning for Landscape Planning: Implications for Policy and Practice from and End-User's Perspective', International Archives of Photogrammetry, Remote Sensing and Spatial Information Sciences, XXXVI.

Steinitz, C. (1979) Defensible processes for regional landscape design. American Society for Landscape Architects.

Steinitz, C. 2013. Geodesign: Past, Present, and Future. Beginnings of Geodesign: A Personal Historical Perspective. ESRI.

Stoter, J. and Zlatanova, S. '3D GIS, where are we standing?', Joint Workshop on Spatial, Temporal, and MultiDimensional Data Modelling and Analysis, Quebec City, Canada, 2-3 October, 6.

Szukalski, B. (2011) A 3D GIS and GeoDesign Milestone: ESRI. Available at: https://blogs.esri.com/esri/esriinsider/2011/08/11/3d-gis-and-geodesign/.

Tae-Woo Kim, Yang-Won Lee and Suh, Y.-C. 'A Literature Study on 3D Topology Models for The 3D Spatial Analysis'. Asian Conference in Remote Sensing, Hanoi Vietnam.

Wheeler, C. (2010) 'Designing GeoDesign', GeoDesign Summit.

Widodo, K., Damayanti, V. D. and Hadi, S. (2012) 'Perencanaan Lanskap Sungai Kelayan Sebagai Upaya Revitalisasi Sungai di Kota Banjarmasin Kalimantan Selatan', Jurnal Lanskap Indonesia, Vol. 4(No. 1).

$\mathrm{Xu}$, Y. (2011) 'Application of GIS Spatial Analysis Method in Landscape Planning and Design - A Case Study of Integrated Land-Use Suitability Analysis of Nanjing Zhongshan Scenic Area', in Zhou, M. \& Tan, H. (eds.) Advances in Computer Science and Education Applications: International Conference, CSE 2011, Qingdao, China, July 9-10, 2011. Proceedings, Part II. Berlin, Heidelberg: Springer Berlin Heidelberg, pp. 67-73. 